\title{
Anotações sobre a modernidade líquida em Once Upon a Time
}

\section{Notes on liquid modernity in Once Upon a Time}

Marcos Aleksander Brandão ${ }^{1}$ e Laura Cánepa ${ }^{2}$

1 Doutorando do Programa de Pós-Graduação em Comunicação da Universidade Anhembi Morumbi (UAM). E-mail: profmarcosbrandao@gmail.com.

2 Docente do Programa de Pós-Graduação em Comunicação da Universidade Anhembi Morumbi (UAM). Doutora em Multimeios pela Unicamp. E-mail: laurapoa@hotmail.com. 


\section{Resumo}

Este trabalho discute o seriado televisivo Once Upon a Time, da rede de televisão estadunidense $A B C$, que realiza uma releitura contemporânea dos contos de fadas. Sugere-se que aspectos da modernidade líquida descritos pelo sociólogo Zygmunt Bauman - como fluidez, fragmentação, incerteza e volatilidade - afetam e ajudam a moldar peças audiovisuais de sucesso, como a série em questão. Consideramos que, em Once Upon a Time, esses aspectos se expressam por meio de duas estratégias principais: a divisão do mundo diegético em mundos paralelos e a reinvenção de personagens de narrativas tradicionais. A partir dessas estratégias, a série traça o caminho da sua protagonista, Emma Swan, que busca dar sentido à existência num mundo atravessado por imaginários construídos pelos produtos midiáticos e também por noções instáveis de identidade, história e passado.

Palavras-chave

Televisão, séries, EUA, Once upon a time, modernidade líquida.

\section{Abstract}

This paper discusses the ABC TV series Once Upon a Time created by the network as a contemporary adaptation of fairy tales. We suggest that aspects of liquid modernity described by the sociologist Zygmunt Bauman - such as fluidity, fragmentation, uncertainty, and volatility affect and help to shape successful audiovisual pieces. We consider that in Once Upon a Time these aspects are expressed through two main strategies: the fragmentation of the diegetic world and the reinvention of characters from traditional narratives. From these strategies, the series traces the path of its protagonist, Emma Swan, who searches for meaning to exist in a world crossed by imagery constructed by media products and also by unstable notions of identity, history and past.

\section{Keywords}

Television, series, USA, Once upon a time, liquid modernity. 
Há uma despreocupada consciência de que existem muitas histórias que precisam ser contadas e recontadas repetidamente,

a cada vez perdendo algo e acrescentando algo às versões anteriores. Há também uma nova determinação: a de resguardar as condições nas quais todas as histórias podem ser contadas, recontadas e contadas novamente de forma diversa (Zygmunt Bauman, 1999, p. 259).

Era uma vez um seriado de televisão que, para contar um conto, precisou aumentar alguns pontos, mas que, para aumentar esses pontos, precisou de muitos outros contos. Para iniciar este artigo, precisamos, primeiramente, entender o que nos motivou a escrevê-lo, e quais as razões para estruturá-lo de acordo com concepções da contemporaneidade, que, em nossa opinião, refletem-se no modo como algumas peças audiovisuais vêm sendo configuradas.

Um aspecto que chama a atenção, hoje, em algumas narrativas populares da televisão, do cinema, dos quadrinhos, dos jogos eletrônicos e da literatura é a recorrência do imaginário legado pelos contos de fadas tradicionais. Estejam eles recontados em versões relativamente fiéis aos originais, como no filme Cinderela (Kenneth Brannagh, EUA, 2015); recriados em séries animadas de TV como A hora da aventura (de Pendleton Ward, exibida desde 2010 no Cartoon Network); ou remixados em mashups ${ }^{3}$ como a série de quadrinhos Fábulas (de Bill Willingham, publicada pela DC Comics desde 2002), o fato é que os velhos contos de fadas continuam relevantes para a cultura contemporânea.

O seriado televisivo de drama-fantasia Once Upon a Time é, atualmente, um dos exemplos mais conhecidos dessa tendência. Criado pelos roteiristas Adam Horowitz e Edward Kitsis, teve sua estreia mundial nos EUA, no dia 21 de outubro de 2011, com transmissão pela rede ABC. No Brasil, vem sendo exibido pelo Canal Sony desde abril de 2012, e também via streaming, na Netflix. Em 2017, Once Upon a Time encerrou sua sexta temporada, fechando o arco narrativo da seller Orgulho e Preconceito e Zumbis (Seth Grahame-Smith, 2009). O livro trazia uma "mistura" do clássico de Jane Austen com uma aventura de horror repleta de jovens virginais combatendo monstros comedores de carne humana. O sucesso originou outras obras, tanto na literatura quanto em outras mídias. 
personagem Emma Swan (interpretada por Jennifer Morrison), que se iniciou na primeira temporada. A série foi renovada para a sétima temporada, mas agora terá novos protagonistas. Cada uma das temporadas já finalizadas teve 22 episódios ${ }^{4}$ de 45 minutos de duração, alcançando uma audiência que passou da casa dos dez milhões de espectadores nos EUA ${ }^{5}$. Ainda hoje, Once Upon a Time é uma das séries mais populares da televisão mundial, o que pode ser verificado em redes sociais que reúnem seus fãs. No Twitter, por exemplo, o perfil oficial da série ultrapassa a marca de um milhão e seiscentos mil seguidores, enquanto esse número sobe para mais de seis milhões e duzentos mil seguidores no Facebook ${ }^{6}$.

A história de Once Upon a Time se passa na fictícia cidade de Storybrooke, no estado do Maine, na região da Nova Inglaterra, nos EUA. Conforme somos informados no episódio-piloto, os moradores de Storybrooke são, na verdade, personagens de contos de fadas - ou também seres mitológicos, ou figuras literárias famosas - que foram transportados, 28 anos antes, da Floresta Encantada onde viviam para o século XXI . Nessa passagem, tiveram suas memórias, poderes mágicos e finais felizes roubados em função de uma poderosa maldição obtida por Rumplestiltskin ${ }^{8}$ (Robert Carlyle) e lançada pela Rainha Má (Lana Parrilla). Vivendo o "nosso mundo", cada uma das personagens de Once Upon a Time ganha uma nova identidade, adaptada à realidade compartilhada no "mundo real" pelos espectadores da série. Na descrição de Maria Zilda Cunha:

Once Upon a Time é uma série televisiva que realiza uma releitura dos contos de fadas e contos maravilhosos para o público adulto. Personagens amplamente conhecidos pelo público espectador são retirados de seu lugar "originário" - os contos clássicos infantis - e refuncionalizados, recebem 
outros atributos, outras configurações e novas provas. O sintagma "era uma vez" dá início à narrativa, mas o espectador logo se depara com um espaço que frustra a expectativa de conhecedores de contos de encantamento e de magia. Diferentemente de palácios e de florestas encantadas, as personagens estão - como nós -, imersas no mais banal cotidiano. Todos se acham presos em um mundo sem magia, sem memória, um lugar onde todos os finais felizes Ihes foram roubados (CUNHA, 2016, p. 15).

Porém, nesse contexto desencantado descrito por Cunha, há uma personagem capaz de recuperar a magia e a felicidade prometidas pelos contos de fadas, Emma Swan. Ela é filha da princesa Branca de Neve (Ginnifer Goodwin) e de seu Príncipe Encantado (Josh Dallas), mas foi enviada, ao nascer, da Floresta Encantada para a cidade de Boston, nos EUA, logo antes da maldição ser lançada. Desde então, ela cresceu em lares adotivos, passando por várias famílias, e sempre questionando o motivo de ter sido abandonada pelos pais, cujas identidades ela desconhece.

Livre da maldição, mas também herdeira inconsciente do mundo dos contos de fadas, Emma vai descobrir que está destinada a restaurar as memórias perdidas das personagens que conhecerá ao longo de sua jornada. Ela é convocada à aventura no dia de seu vigésimo oitavo aniversário ${ }^{9}$, quando recebe a visita de seu filho Henry Daniel Mills (Jared S. Gilmore), de dez anos de idade - cujo pai, o misterioso Neal Cassidy ${ }^{10}$ (ou Baelfire, interpretado por Michael RaymondJames), vem a ser o primogênito de Rumplestiltskin. Henry chega sozinho à casa de Emma, em Boston, informando-a de que ela será a principal responsável por salvar as personagens dos contos de fadas. O menino carrega consigo um livro intitulado Once Upon a Time, que detém parte do segredo para que a maldição seja desfeita. O livro também descreve a trajetória de uma "Salvadora" (Emma) que levará as personagens a uma grande batalha final. Henry solicita que sua

A idade de 28 anos de Emma não parece casual. Para a astrologia - cujo imaginário é tantas vezes relacionado ao pensamento mágico medieval e às narrativas maravilhosas -, 28 anos correspondem ao tempo que o planeta Saturno leva para retornar ao ponto do céu em que estava na data de nascimento de uma pessoa. O primeiro "Retorno de Saturno" indica a entrada definitiva da idade adulta, representando o processo de amadurecimento. 
mãe o acompanhe em sua viagem de volta até a cidade de Storybrooke. Ela, ainda incrédula, mas desejando encerrar logo o relacionamento com o garoto, concorda em levá-lo. O que Emma não sabe é que Henry foi adotado pela própria Rainha Má - Regina Mills, a prefeita da cidade de Storybrooke - que também desconhece a origem da mãe biológica de seu filho.

Essa sequência de coincidências reforça a ideia de um destino previamente traçado, e faz com que Emma encarne o papel da heroína de contos maravilhosos ${ }^{11}$ - estes, por sua vez, derivados de modelos mitológicos que deram origem a estudos descritivos como os de Vladimir Propp (2001), Joseph Campbell (2007) e Christopher Vogler (2006), entre outros autores. Quando chamada à aventura por seu filho, ela vive o momento crucial que dá início a essas histórias, como explica Campbell:

Esse primeiro estágio da jornada mitológica - o que denominamos aqui "o chamado da aventura" - significa que o destino convocou o herói e transferiu-lhe o centro de gravidade do seio da sociedade para uma região desconhecida. Essa fatídica região dos tesouros e perigos pode ser representada sob várias formas: como terra distante, uma floresta, um reino subterrâneo, a parte inferior das ondas, a parte superior do céu, uma ilha secreta, o topo de uma elevada montanha ou um profundo estado onírico. Mas sempre é um local habitado por seres estranhamente fluidos e polimorfos, de tormentos inimagináveis, façanhas sobre-humanas e delícias impossíveis (CAMPBELL, 2007, p. 66).

A personagem Emma ocupa uma posição especial na concepção de Once Upon a Time. Ela foi criada exclusivamente para a série, mas pensada como um amálgama capaz de interagir com figuras clássicas muito conhecidas pelo público, como as princesas Cinderela (na série, interpretada por Jessy Schram) e Bela Adormecida (vivida por Sarah Bolger). Em meio a essas personagens sobrecarregadas de um imaginário coletivo que se apresenta em inúmeras camadas

11 A relação dos contos de fadas com o gênero maravilhoso é aqui entendida conforme Todorov: "o conto de fadas não é senão uma das variedades do maravilhoso e os acontecimentos sobrenaturais aí não provocam qualquer surpresa: nem o sono de cem anos, nem o lobo que fala, nem os dons mágicos das fadas" (2014, p. 60). 
de sentidos, Emma, uma moça aparentemente comum, será transformada na única criatura com o poder verdadeiro de reencantar suas vidas.

Tendo como base a trama principal e algumas estratégias narrativas adotadas pela série, sugerimos que Once Upon a Time reproduz certa experiência comum aos espectadores contemporâneos, tomados por um sentido de urgência e desorientação que os faz circular, como Emma Swan, entre fragmentos de imaginários diluídos de obras constantemente reaproveitadas e recicladas. Para realizar nosso percurso analítico, recorreremos às reflexões de Zygmunt Bauman sobre a modernidade líquida (2001), que nos auxilia a compreender dois recursos fundamentais utilizados pelos criadores da série: a divisão da diegese em mundos paralelos e a reinvenção de personagens oriundas de narrativas tradicionais.

\section{Algumas palavras sobre a complexidade narrativa em Once Upon a Time}

As séries de televisão se encontram, hoje, em um dos momentos de maior popularidade de sua história. Como ressaltam Pontes e Santos, o crescimento dessas produções nos últimos 20 anos é significativo: em 1999, os canais a cabo dos EUA lançaram 23 novas séries; em 2014, foram 180 novas produções seriadas (2016, p. 1). Para Marcel Silva, "três condições se consubstanciaram para promover esse panorama em que as séries ocupam lugar destacado dentro e fora dos modelos tradicionais de televisão" (2014, p. 243). Segundo ele, a primeira condição é a forma, que "está ligada tanto ao desenvolvimento de novos modelos narrativos, quanto à permanência e à reconfiguração de modelos clássicos" (SILVA, 2014, p. 243). A segunda condição, por sua vez, está relacionada, para o autor, "ao contexto tecnológico em torno do digital e da internet, que impulsionou a circulação das séries em nível global" (SILVA, 2014, p. 243). Por fim, a terceira condição, segundo Silva, refere-se "ao consumo desses programas, seja na dimensão espectatorial do público, através de comunidades de fãs e de estratégias de engajamento, seja na criação de espaços noticiosos e críticos" (2014, p. 243).

Nosso interesse aqui é destacar a primeira condição apontada por Silva: o desenvolvimento dos modelos narrativos. Como propõe Jason Mittell, uma 
das características dos seriados televisivos desde o final do século XX é a sua complexidade narrativa. Tal denominação não é valorativa ${ }^{12}$, mas tem o objetivo de descrever estratégias que promovem um novo tipo de fruição calcado em desafios às regras da narração televisiva convencional (MITTEL, 2012, p. 44).

Mittell destaca, em séries contemporâneas como Lost (ABC, 2004-2010) e 24 Horas (FOX, 2001-2010), alguns aspectos que caracterizam a complexidade narrativa, entre os quais a articulação de diversos gêneros, a desorientação provocada deliberadamente pelas tramas e a expansão do papel dos arcos narrativos entre episódios e temporadas (2012, p. 37; 44). Segundo Mittel, os espectadores de séries como essas veem-se entregues à observação atenta dos processos discursivos, transformando-se em "narratologistas amadores", capazes de perceber os usos e violações de regras, recuperar cronologias e evidenciar inconsistências ou continuidades (2012, p. 49). Isso faz com que a estética operacional seja trazida ao primeiro plano, "chamando atenção para a natureza construída da narração, e demandando admiração direcionada a como os escritores conseguiram realizá-la" (MITTEL, 2012, p. 43).

Once Upon a Time pode ser vista como um exemplo ilustrativo de complexidade narrativa. Como descreve Sandra Valenzuela, a série constitui "uma adaptação dos contos de fadas, no entanto, o seu principal interesse consiste em entender como tantas narrativas entrelaçadas desenham um argumento novo" (2016, p. 29). Esse procedimento descrito por Valenzuela chama a atenção para o que Mittell considera "uma qualidade barroca e com consciência formal, pela qual assistimos ao processo de narração como uma máquina, mais do que nos engajamos em sua diegese" (2011, p. 43). De fato, pode-se dizer que, ao espectador de Once Upon a Time, interessa tanto saber o destino de Emma Swan quanto deleitar-se com as reviravoltas e mudanças promovidas em histórias já muito conhecidas, num tipo de "pirotecnia narrativa" (MITTELL, 2012, p. 44) muito semelhante à das séries mencionadas por Mittell. 
Once Upon a Time também pode ser considerada uma narrativa complexa por atravessar vários gêneros, apresentando em seus episódios não só elementos da fantasia ou do maravilhoso, mas também do horror, do melodrama romântico, do drama familiar, da comédia e do mistério. Cada um desses gêneros colabora para a estruturação da trama, reforçando a ideia de que, nessa série, quaisquer contos ou mitos conhecidos podem ser incorporados, num movimento que permite aos diversos fragmentos misturarem-se e coexistirem numa mesma paisagem, sem qualquer preocupação com o realismo ou com a tradição que envolve as histórias originais. Assim, princesas de contos de fadas da Europa Central (como a já mencionada Branca de Neve) podem conviver com criaturas da mitologia grega (como a divindade Hades e o monstro ctônico Medusa), que não estão impedidas de interagir com personagens clássicas da literatura mundial (como o Dr. Jekyll, de Robert Louis Stevenson).

Além disso, a série apresenta linhagens familiares, romances e alianças políticas surpreendentes. Por exemplo, ao longo da trama, o espectador verá a filha da Branca de Neve (Emma) viver um romance com o Capitão Gancho (Colin O’Donoghue). Já o conhecido antagonista do Capitão Gancho, Peter Pan (Robbie Kay), vem a ser, conforme a série revelará, avô do menino Henry, filho de Emma. Também a mãe adotiva de Henry (a temida Rainha Má), será identificada como irmã da Bruxa Má do Oeste (de O Mágico de Oz), e ambas como filhas da Rainha de Copas, de Alice no País das Maravilhas. Não por acaso, diversos estudiosos, jornalistas e fãs da série disponibilizam árvores genealógicas das personagens (AZUBEL, 2017, p. 154; BUDAG, 2017, p. 41) para auxiliar a compreensão e o acompanhamento da história - o que confirma a observação de Mittell quanto ao tipo de fruição favorecida pela série.

Mas não se trata apenas de uma combinação de gêneros e de personagens conhecidas. Como já destacamos, Once Upon a Time também articula seu universo de fantasia ao nosso mundo "real", colocando criaturas mágicas em situações banais. Com isso, amplia as possibilidades de variação e combinação das situações narrativas, chamando a atenção, como descreve Mittell, para a sua 
"natureza construída" (2012, p. 43). Essa introdução das personagens de contos de fadas no nosso mundo parece ter também uma outra função, que nos interessa particularmente neste artigo: a de fazer com que a própria ideia do cotidiano contemporâneo seja, de certo modo, desafiada pela introdução de elementos que eliminam separações entre o universo específico da série e o dos contos de fadas e entre representações do mundo histórico e de diferentes tradições mitológicas.

\section{Personagens que habitam mundos paralelos}

A sustentação da complexa arquitetura narrativa de Once Upon a Time depende, em grande parte, de um recurso fundamental: a divisão do mundo diegético em dois espaços-tempos paralelos (ou cronotopos ${ }^{13}$ paralelos) habitados pelas mesmas personagens. De um lado, está a Floresta Encantada, congelada no tempo e no espaço; de outro, Storybrooke, cidade aparentemente típica dos EUA no século XXI. Tal divisão se complica pelo fato da Floresta Encantada não se apresentar como um tempo-espaço unificado, e sim como uma coleção de portais para outros mundos fantásticos: "[tais] portais fazem os espaços-temporais se tocarem e permitem o deslocamento instantâneo de um a outro cronotopo, de maneira definitiva ou temporária" (BUDAG, 2017, p. 84). E isso não é tudo. Como descreve Budag:

Muito frequentemente, a narrativa do cronotopo do Mundo Real é interrompida para dar espaço à narrativa do cronotopo de outrora, do Reino Encantado. [...] Once upon a time ainda insere um ingrediente a mais neste jogo de temporalidades: quando retorna do mundo fantástico, o mundo real/contemporâneo é tomado a partir de outra perspectiva. Para ilustrar, podemos citar situação ocorrida no sétimo episódio (The heart is a lonely hunter): quando, no Reino Encantado, o Caçador mata um cervo, a narrativa é retomada em Storybrooke com sua contraparte, o xerife Graham, sonhando com um cervo. Um cronotopo interfere no outro (BUDAG, 2016, p. 83). 
Sabe-se que a existência paralela das personagens em tempos e espaços diferentes, como a que se observa em Once Upon a Time, é um recurso recorrente nos seriados de fantasia realizados nos últimos anos. Como observa Mauro Pommer, hoje, uma notável tendência nas obras audiovisuais é a narração da história dos protagonistas através de linhas de vidas paralelas (2011, p. 29). Segundo o autor:

Desde os super-heróis que banalizaram esse gênero de abordagem até os humanos que vivem vidas duplas como seres mitológicos encarnados, as histórias passam por imensa gama de variantes desse modelo de base, incluindo como protagonistas cidadãos comuns levados a desenvolver atividades secretas paralelas em resposta às circunstâncias extremas a que suas vidas se encontram submetidas (POMMER, 2011, p. 29).

Pommer faz questão de destacar que "vidas paralelas não aparecem necessariamente como sinônimo de superpoderes" (2011, p. 30), como se verifica em Breaking Bad (AMC, 2008-2011) e Mad Men (AMC, 2007-2011), por exemplo. No entanto, reconhece que o mais comum é que essas vidas paralelas funcionem como alternativas mágicas ou inexplicáveis, em séries como Lost e True Blood (HBO, 2008-2011), ou ainda em franquias de longas-metragens como Avatar (James Cameron, 2009) (POMMER, 2011, p. 30). Assim, diante do que percebe como uma reiteração desse recurso, Pommer acredita que o fenômeno repercute "uma crescente tendência social a tomar como natural ou inevitável a bipartição do sujeito contemporâneo entre papéis diferentes e muitas vezes inconciliáveis" (2011, p. 29). Essa bipartição, por sua vez, segundo ele, "pode ser interpretada como um resultado possível da compressão existencialmente experimentada na vivência do espaço e do tempo, característica da modernidade" (POMMER, 2011, p. 29).

Ainda que não se refira diretamente ao trabalho de Zygmunt Bauman, Pommer parece identificar algo que se aproxima da ideia de liquidez atribuída pelo sociólogo polonês à experiência da modernidade tardia. Como explica Bauman:

Diferentemente da sociedade moderna anterior, que chamo de "modernidade sólida", que também tratava sempre de desmontar a realidade herdada, a de agora não o faz com uma perspectiva de longa 
duração [...]. Tudo está agora sendo permanentemente desmontado mas sem perspectiva de alguma permanência. [...] É por isso que sugeri a metáfora da "liquidez" para caracterizar o estado da sociedade moderna: como os líquidos, ela caracteriza-se pela incapacidade de manter a forma. Nossas instituições, quadros de referência, estilos de vida, crenças e convicções mudam antes que tenham tempo de se solidificar em costumes, hábitos e verdades "auto-evidentes". Sem dúvida a vida moderna foi desde o início "desenraizadora", "derretia os sólidos e profanava os sagrados", como os jovens Marx e Engels notaram. Mas enquanto no passado isso era feito para ser novamente "re-enraizado", agora todas as coisas empregos, relacionamentos, know-hows etc. - tendem a permanecer em fluxo, voláteis, desreguladas, flexíveis (BAUMAN, 2004, p. 321-322).

Segundo Annalice Pillar, para Bauman, "duas características se apresentam de modo insistente em nosso cotidiano, passando a constituir-se como problemáticas contemporâneas: a simultaneidade de ações e linguagens; e a ambivalência nas formas de ser e agir" (2013, p. 306, grifos nossos). Segundo essa autora, "a simultaneidade faz parte tanto de nossas atividades rotineiras quanto dos modos de ver e dizer sobre nossa época" (PILLAR, 2013, p. 306), enquanto a ambivalência diz respeito "à inquietação e desconforto que experimentamos pela presença, ao mesmo tempo, de atitudes/posições opostas, que poderiam ser consideradas contraditórias e excludentes, mas que se apresentam como complementares" (PILLAR, 2013, p. 306).

Nesse contexto, as noções de tempo e de espaço, que já vinham se modificando desde o começo da modernidade, apresentam desafios a partir de valores como a simultaneidade, a instabilidade, a efemeridade. Para Bauman, o mundo que habitamos nos dias de hoje pode ser percebido "como um 'território flutuante' em que 'indivíduos frágeis' encontram uma 'realidade porosa'" (2001, p. 238) $)^{14}$. A esse território, segundo Bauman, "só se adaptam coisas ou pessoas fluidas, ambíguas, num estado de permanente transformar-se, num estado constante de autotransgressão. O 'enraizamento', se existir, só pode ser dinâmico: ele deve ser reafirmado e reconstituído diariamente" (BAUMAN, 2001, p. 238). Assim, os 
indivíduos precisam "acostumar-se ao estado de desorientação perpétua, a viajar por estradas de rumo e tamanho desconhecidos [...]; precisam concentrar toda sua atenção no pequeno trecho da estrada que têm de vencer antes do escurecer" (BAUMAN, 2001, p. 239). Quando nos colocamos diante dos diferentes cronotopos de Once Upon a Time, e acompanhamos as idas e vindas das personagens, com experiências e trajetórias que se refazem a cada novo episódio, é possível perceber que a série, em certo sentido, mergulha nessa liquidez que, para Bauman, caracteriza o nosso espaço-tempo atual.

A ligação de Once Upon a Time com a experiência social contemporânea já foi observada por autoras que relacionaram a série à ideia de pós-modernidade (como se verifica, por exemplo, em trabalhos de Budag ${ }^{15}$ e Larissa Azubel ${ }^{16}$ ). De fato, as perspectivas críticas à modernidade que estão na base das discussões sobre a pós-modernidade têm pontos de convergência com o discurso de Bauman, como explica Miriam Adelman (2009, p. 197). Segundo a autora, nos trabalhos O mal-estar da pós-modernidade (1998) e Modernidade e ambivalência (1999), Bauman partiu "daquilo que se tornou a preocupação fundamental dos filósofos pós-modernos [...]: como é que os sonhos [de libertação] modernos rapidamente produzem discursos e tentativas práticas de homogeneização e controle" (ADELMAN, 2009, p. 195).

Para Adelman, porém, Bauman tem uma visão ambivalente das considerações pós-modernas. O sociólogo polonês, por um lado, vê "na desestabilização pósmoderna dos padrões rígidos da vida social da modernidade, algo de salutar ou potencialmente emancipatório" (ADELMAN, 2009, p. 198). Por outro lado, para Bauman, os desafios e os perigos da pós-modernidade seriam enormes, uma vez que "ao contrário da ciência e da ideologia política, a liberdade não contemporâneo. Afinal [...] nossas concepções e vivências de tempo e espaço se modificaram intensamente no trajeto percorrido entre a sociedade pré-moderna e a atual, pós-moderna" (2017, p. 85, grifo nosso). da pós-modernidade, que cristalizou pulsões subjetivas e intimações objetivas do meio social" (2017, p. 414, grifo nosso). Segundo ela, Once Upon a Time pode ser considerada uma "versão pós-moderna dos contos de fadas"(AZUBEL, 2017, p. 152, grifo no original). 
promete nem certeza, nem garantia de nada" (BAUMAN, apud ADELMAN, 2009, p. 199). Assim, na modernidade líquida - termo que Bauman passou a usar para se referir aos nossos tempos, preferindo-o ao termo pós-modernidade ${ }^{17}$-, as pessoas estão constantemente seduzidas por aventuras de curta duração e por novas experiências, sem fixar-se a modelos e caminhos predeterminados. Essa urgência por novidades, ainda que libertadora e criativa, pode levá-las a um ponto de desorientação - que parece ser muito semelhante àquele em que as personagens se encontram em Storybrooke, cidade descrita por Valenzuela como "uma distopia ficcional do presente" (2016, p. 217).

\section{Identidades múltiplas}

Os diversos cronotopos de Once Upon a Time sustentam outra característica da série: a copresença não apenas de personagens dos mais variados contos de fadas, lendas e mitos, mas também (e sobretudo) a recomposição da identidade delas. Esse procedimento está ligado à estrutura intertextual da narrativa de Once Upon a Time, que é uma das características mais amplamente examinadas por quem se dedica a estudar a série. Afinal, trata-se de uma obra que não somente se apoia em outros textos (narrativos, imagéticos, sonoros), utilizando-os com virtuosismo (como se percebe na interligação de contos de fadas, literatura, mitologias e conhecimentos esotéricos), como também produz uma complexa estrutura interna na qual diferentes cronotopos se interligam numa mesma narrativa, citando uns aos outros. Como descreve Budag: que não distingue sociologia pós-moderna de sociologia da pós-modernidade, 'pós-modernismo' de 'pós-modernidade'. No meu vocabulário, 'pós-modernidade' significa uma sociedade (ou, se se prefere, um tipo de condição humana), enquanto 'pós-modernismo' refere-se a uma visão de mundo que pode surgir, mas não necessariamente, da condição pós-moderna. Procurei sempre enfatizar que, do mesmo modo que ser um ornitólogo não significa ser um pássaro, ser um sociólogo da pós-modernidade não significa ser um pós-modernista, o que definitivamente não sou. [...] [E] u sempre estive interessado na sociologia da pós-modernidade, ou seja, meu tema tem sempre sido compreender esse tipo curioso e em muitos sentidos misterioso de sociedade que vem surgindo ao nosso redor; e a vejo como uma condição que ainda se mantém eminentemente moderna na suas ambições e modus operandi (ou seja, no seu esforço de modernização compulsiva, obsessiva), mas que está desprovida das antigas ilusões de que o fim da jornada estava logo adiante. É nesse sentido que pós-modernidade é, para mim, modernidade sem ilusões" (BAUMAN, 2004, p. 321). 
dentro das duas textualidades/mundos em que corre o grande texto da produção cultural em análise, há duas grandes camadas de relações intertextuais que se constroem e se cruzam de maneira mais complexa do que a pressuposta inicialmente. Em uma primeira camada, acontecem referências a textos externos a sua narrativa, em sua maioria contos de fada, mas também textos culturais outros. Eles podem estar referenciados em uma textualidade/mundo ou em outra, ou em ambas. Já na segunda camada de relações intertextuais, acontecem as menções internas à narrativa nela mesma: de uma textualidade/mundo a sua outra textualidade/mundo (BUDAG, 2017, p. 256).

A protagonista, é, ao seu modo, exemplar desse jogo intertextual descrito por Budag. Apesar de ser filha da Branca de Neve, ela tem uma trajetória que pode ser relacionada ao conto do Patinho Feio, conforme declarado pelo próprio criador da série, Edward Kitsis (VALENZUELA, 2016, p. 88). A personagem clássica das histórias infantis é um filhote de cisne que foi chocado fora de seu ninho, por uma pata. Por ser muito diferente dos irmãos, ele acaba sendo rejeitado, mas, na medida em que cresce, descobre ser, na verdade, uma das aves mais encantadoras e belas da natureza: um cisne. De certo modo, pode-se dizer que a jornada de Emma, uma mulher abandonada e insegura que se descobre figurachave de um mundo encantado, pode ser comparada à do Patinho Feio. Vale aqui ressaltar, nesse sentido, que, na sexta temporada de Once Upon a Time, no início do episódio 11, encontramos Emma criança, vivendo nas ruas, até que, num determinado momento, certo jovem (Pinóquio) conta a ela a história do Patinho Feio, afirmando que, se tivermos fé, todos nós podemos nos tornar lindos cisnes. No mesmo episódio, descobrimos que foi a partir desse momento que a personagem adotou o seu último nome, Swan (cisne, em inglês).

Mas a escolha do cisne não se restringe ao conto do Patinho Feio. Ela também faz referência a histórias tradicionais envolvendo as figuras dos cisnes branco e negro, entre elas $O$ lago dos cisnes, famoso ballet composto por Tchaikovsky para a companhia russa Bolshoi, em 1877. No libreto escrito por Vladimir Begitchev e Vasily Geltzer, conhecemos a história da princesa Odette, uma jovem aprisionada no corpo de um cisne branco por um feiticeiro. Vivendo no entorno de um lago 
formado pelas lágrimas de sua mãe, Odette se mantém quase todo o tempo em condição animal, revelando-se humana somente por algumas horas da noite. Para se libertar da maldição, ela precisa que um jovem admirador lhe declare amor e fidelidade - no caso, o Príncipe Siegfried - mas ele acaba sendo enganado pela irmã gêmea de Odette (Odile, o Cisne Negro). A oposição entre as gêmeas Odette e Odile muitas vezes foi tratada como representação da ambiguidade humana entre o Bem e o Mal, numa dinâmica frequente das histórias fantásticas. E Emma não estará livre dela: o final da quarta temporada de Once Upon a Time termina com a Salvadora absorvendo toda a força maligna da cidade Storybrooke. Nos capítulos iniciais da quinta temporada, é revelado que Emma se tornou a nova Senhora das Trevas, e ela passará os próximos episódios lutando entre os poderes da Luz (o Bem) e das Trevas (o Mal).

Mas, se encarnações do cisne são importantes para compreendermos a concepção da personagem Emma Swan, seu primeiro nome também traz camadas sobrepostas de significados e referências. A palavra "Emma/Imma", que tem origem germânica, significa "todo" ou "universal". O nome se tornou muito popular por volta do ano 1000, através da Rainha Emma, da Normandia18. Quando escrito ao contrário, o nome também remete à palavra alemã "amme", que significa "governanta", "cuidadora" ("ama", em língua portuguesa). Já o nome de seu filho, "Henry", tem origem britânica e significa "o governante de casa". Ele é proveniente do nome germânico Heimirich, que, como Henry, foi usado por diferentes reis ao longo da história ${ }^{19}$. Se observarmos, ainda, a "dupla" Emma e Henry, chegamos ao poema de amor trágico intitulado Henry \& Emma (1709), escrito pelo poeta inglês Matthew Pior, responsável por popularizar o uso desses dois nomes na Inglaterra, a partir do século XVIII.

Num primeiro momento, o conceito de palimpsesto (página manuscrita sobre outra, parcialmente apagada), que foi reivindicado por escritores pós-modernos como 
Umberto Eco (em O nome da rosa, 1980), pode ser útil para a compreensão das operações intertextuais acima descritas, que se disseminam por todos os aspectos de Once Upon a Time. Conforme Gérard Genette, no sentido figurado, os palimpsestos (que podem ser compreendidos literalmente como hipertextos) são obras derivadas de uma obra anterior, por transformação ou por imitação (GENETTE, 2006, p. 5).

No entanto, acreditamos que, em Once Upon a Time, a diluição e o descentramento das personagens originais pode ultrapassar a ideia de palimpsesto, despertando outras ideias que gostaríamos de sugerir, e que estão intrinsecamente ligadas ao universo dos contos maravilhosos: as ideias de transmutação (referente à transformação de um elemento químico em outro ${ }^{20}$ ) e de alquimia (referente ao trabalho espiritual metaforizado na combinação de elementos químicos que possibilitem a transformação de qualquer metal em ouro). Quando observamos os desdobramentos ocorridos com algumas personagens de Once Upon a Time, as ideias de transmutação e de alquimia se mostram produtivas.

Por exemplo, Rumplestiltskin - que também encarna, não por acaso, o Sr. Gold de Storybrooke -, divide-se ainda no papel do Crocodilo dos contos de Peter Pan, na Fera do conto de A Bela e a Fera, e também vive um demônio (o Senhor das Trevas). Sua personalidade manipuladora (de si e de outros) não é apenas "hipertextual", mas consiste em transformações constantes e em estranhas sínteses que não apenas ressignificam as fontes das personagens originais, mas as colocam em permanente estado de fluxo e transformação. Nesse caso, mais uma vez, podemos nos aproximar da ideia de liquidez. Para Bauman:

os líquidos, diferentemente dos sólidos, não mantêm sua forma com facilidade. Os fluidos, por assim dizer, não fixam o espaço, nem prendem o tempo. Enquanto os sólidos têm dimensões espaciais claras, mas neutralizam o impacto e, portanto, diminuem a significação do tempo (resistem efetivamente a seu fluxo ou o tornam irrelevante), os fluidos não se atêm muito a qualquer forma e estão constantemente prontos (e propensos) a mudá-la (BAUMAN, 2001, p. 8). 
Como Rumplestiltskin, os habitantes de Storybrooke são figuras instáveis, em busca de alguma forma definitiva que possa devolver algum sentido unificado a suas existências - mas essa busca é sempre desviada por novas e por vezes imprevisíveis transformações. As personagens, a seu modo, ilustram a descrição de Bauman sobre as condições de existência da modernidade líquida (em contraposição ao que ele chama de modernidade sólida):

\begin{abstract}
São esses padrões, códigos e regras [da modernidade sólida] a que podíamos nos conformar, que podíamos selecionar como pontos estáveis de orientação e pelos quais podíamos nos deixar depois guiar, que estão cada vez mais em falta. Isso não quer dizer que nossos contemporâneos sejam guiados tão somente por sua própria imaginação e resolução e sejam livres para construir seu modo de vida a partir do zero e segundo sua vontade, ou que não sejam mais dependentes da sociedade [...]. Mas quer dizer que estamos passando de uma era de "grupos de referência" predeterminados a uma outra de "comparação universal", em que o destino dos trabalhos de autoconstrução individual está endêmica e incuravelmente subdeterminado, não está dado de antemão, e tende a sofrer numerosas e profundas mudanças antes que esses trabalhos alcancem seu único fim genuíno: o fim da vida do indivíduo (BAUMAN, 2001, p. 14).
\end{abstract}

O "estado de comparação universal" referido por Bauman nos parece útil para compreender as mudanças vividas pelas personagens de Once Upon a Time, já que suas posições, identidades e escolhas estão sendo constantemente postas em xeque pelas descobertas sobre as suas próprias histórias, que os obrigam a questionar suas certezas, seus planos e a imagem que têm de si mesmas, numa reinvenção constante. Curiosamente, ao falar sobre $O$ mal-estar na pósmodernidade, Bauman também usou a metáfora alquímica. Para ele, "em sua versão presente e pós-moderna, a modernidade parece ter encontrado a pedra filosofal que Freud repudiou como uma fantasia ingênua e perniciosa: ela pretende fundir os metais preciosos da ordem limpa e da limpeza ordeira diretamente do ouro do humano" (BAUMAN, 1998, p. 9, grifos nossos). Para ele, de certo modo, a pós-modernidade oferece como escolha e autorrealização aquilo que a modernidade impunha como necessidade: 
Passados 65 anos que $O$ mal-estar da civilização [de Sigmund Freud] foi escrito e publicado, a liberdade individual reina soberana: é o valor pelo qual todos os outros valores vieram a ser avaliados. Isso não significa, porém, que os ideais de beleza, pureza e ordem que conduziram os homens e mulheres em sua viagem de descoberta moderna tenham sido abandonados [...]. Agora, todavia, eles devem ser perseguidos - e realizados - através da espontaneidade, do desejo e do esforço individuais (BAUMAN, 1998, p. 9).

Como diagnostica o autor no posfácio da edição brasileira de Modernidade líquida, "viver entre uma multidão de valores, normas e estilos de vida em competição, sem uma garantia firme e confiável de estarmos certos, é perigoso e cobra um alto preço psicológico" (BAUMAN, 2001, p. 243). Por isso, segundo ele, "vez por outra, sonhamos com uma 'grande simplificação'; sem aviso, nos envolvemos em fantasias regressivas cujas principais inspirações são o útero materno e o lar protegido por muros" (BAUMAN, 2001, p. 244). Em nossa opinião, a série Once Upon a Time pode ser compreendida como uma dessas "metáforas regressivas" apontadas pelo sociólogo - e, nesse sentido, a protagonista Emma Swan desempenha um papel fundamental.

\section{Emma, protagonista de uma série líquida}

O papel de Emma em Once Upon a Time é o de oferecer respostas às angústias das personagens, dando-lhes a oportunidade de fazerem escolhas conscientes e com algum grau de perenidade. Em troca, ela recebe uma visão ao mesmo tempo mais completa e mágica de sua própria existência no mundo. Tal função desempenhada por Emma se aproxima, em certo sentido, da de uma contadora de contos de fadas - tanto para os habitantes de Storybrooke quanto para os espectadores que a acompanham. De fato, os potenciais ensinamentos contidos nos contos de fadas são parte da atração que estes ainda exercem no mundo de hoje, como já defendia Bruno Bettelheim em seu clássico A psicanálise dos contos de fadas, publicado pela primeira vez em 1976. Para ele, tradicionalmente, a função desses contos era exatamente a de prover respostas que dessem sentido à experiência humana no mundo: 


\begin{abstract}
Se esperamos viver não só cada momento, mas ter verdadeira consciência de nossa existência, nossa maior necessidade, e mais difícil realização, será encontrar um significado para nossas vidas [...]. Em um nível manifesto, os contos de fadas ensinam pouco sobre as condições específicas da vida moderna [...]. Mas, através deles, pode-se aprender mais sobre os problemas interiores dos seres humanos [...] do que com qualquer outro tipo de história [...]. Através dos séculos (quando não dos milênios) durante os quais os contos de fadas, sendo recontados, foram se tornando cada vez mais refinados, e passaram a transmitir ao mesmo tempo significados manifestos e encobertos, passaram a falar simultaneamente a todos os níveis da personalidade humana (BETTELHEIM, 1999, p. 14).
\end{abstract}

Nesse contexto, é interessante observar que o papel de Emma como "Salvadora" em Once Upon a Time está diretamente relacionado à recuperação de memórias capazes de dar sentido e de potencializar saberes das outras personagens, todas elas mergulhadas num espaço-tempo aprisionante e desencantado, pois carente de uma história que Ihe dê sentido. Como aponta Budag, "parece-nos que esses contos podem funcionar como um porto seguro para os atuais sujeitos que vivem na contemporaneidade" (2017, p. 23-24). Nesses termos, para Budag, "numa realidade de identidades fragmentadas, líquidas e efêmeras [...], a análise de uma narrativa atual que resgata com novo olhar âncoras tradicionais do passado pode dar pistas para entender o contexto sociocultural contemporâneo, e seus atores sociais" (BUDAG, 2017, p. 23-24).

Mas qual é a história revelada por Emma aos moradores de Storybrooke? Certamente não é a História reconhecida socialmente como a trajetória da humanidade até o século XXI, e sim a história de um mundo mágico construído sobre centenas de anos de acumulação de narrativas fantásticas que circulam em diferentes sociedades. No entanto, esse mundo fantástico se encontra hoje bem integrado à sociedade capitalista de Once Upon a Time, na qual personagens de origem sobrenatural podem desempenhar as mais variadas funções, como as de professoras, governantes, policiais, ladras, médicas, babás ou agiotas. Nesse mundo mágico, figuras que guardam entre si enormes diferenças (em termos de superpoderes e de experiências de vida) são também etnicamente muito próximas (quase sempre caucasianas) e, em sua grande maioria, 
heterossexuais e monogâmicas. Do mesmo modo, elas priorizam o trabalho com vistas ao desenvolvimento individual, o amor romântico heterossexual, o amor aos filhos e à família nuclear. Com isso, Once Upon a Time, ao mesmo tempo em que moderniza e reorganiza os contos de fadas sob um olhar contemporâneo, sustenta ideais conservadores que estão muito próximos àqueles fornecidos pelos contos de fadas tradicionais. Assim, a série reencanta a contemporaneidade por meio de sua nova história, recontada - mas esta é calcada em valores que se mostram, ao mesmo tempo, e contraditoriamente, líquidos e eternos.

\section{Considerações finais}

Para Bauman, "vivemos em tempos de desregulamentação, de descentralização, de individualização, em que se assiste ao fim da Política com P maiúsculo e ao surgimento da 'política da vida', ou seja, que assume que eu, você e todo o mundo deve encontrar soluções biográficas para problemas históricos, respostas individuais para problemas sociais" (BAUMAN, 2004, p. 308). Isso, segundo ele, faz com que indivíduos sejam, de modo geral, abandonados aos seus próprios recursos. E, nesse processo, não é raro que discursos tradicionais ofereçam um novo apelo, porém agora apresentados como escolhas individuais. Em nossa opinião, é este o processo que pode ser observado no desenvolvimento de Once Upon a Time.

Para conceber este trabalho, concordamos com a pesquisadora Larissa Azubel, no sentido de que a série pode ser vista como uma "tecnologia do imaginário capaz de evidenciar as angústias sociológicas de nosso tempo e de ajudar a interpretar comportamentos e realidades sociais" (2017, p. 413). Como também argumenta Budag, nosso mundo nem sempre tem um sentido claro, o que faz com que muitos sujeitos, como o próprio personagem Henry, possam recorrer a contos maravilhosos para buscar respostas a seus questionamentos e angústias (2017, p. 23).

Once Upon a Time vem sendo discutida por diferentes pesquisadoras no Brasil. Aqui, buscamos contribuir para as discussões já em curso sobre a série, 
propondo a aproximação com o conceito de modernidade líquida. Evidentemente, esta é apenas uma das abordagens possíveis, mas ela nos parece interessante por refletir tanto características formais quanto ideológicas da série. Assim, aspectos recorrentes na descrição da modernidade líquida - como a fragmentação de experiências paralelas, a fluidez com que tais experiências se alternam, a volatilidade dessa alternância e a incerteza causada por todo o processo abundam na complexa narrativa que buscamos descrever, e também nos dão pistas para compreender o porquê de certos aspectos ideológicos da série, que oferece respostas mágicas e individuais para os desconfortos encantadores de nosso tempo presente.

\section{Referências}

ADELMAN, M. Visões da Pós-Modernidade: discursos e perspectivas teóricas. Revista Sociologias, Porto Alegre, v. 11, n. 21, p. 184-217, jan./jul. 2009.

AZUBEL, L. L. R. Uma série de contos e os contos em série: o imaginário pósmoderno em Once Upon a Time. Tese (Doutorado em Comunicação) - Pontifícia Universidade Católica do Rio Grande do Sul, Porto Alegre, 2017.

BAUMAN, Z. Modernidade líquida. Rio de Janeiro: Zahar, 2001.

. Modernidade e ambivalência. Rio de Janeiro: Zahar, 1999.

. O mal-estar da pós-modernidade. Rio de Janeiro: Zahar, 1998. . Entrevista com Zygmunt Bauman concedida a Maria Lúcia Garcia Pallares-

Burke. Revista Tempo Social, São Paulo, v. 16, n. 1, p. 301-325, jun. 2004. Disponível em: <https://goo.gl/S5ALTR>. Acesso em: 13 out. 2017. 
BETTELHEIM, B. A psicanálise dos contos de fadas. 13. ed. Rio de Janeiro: Paz e Terra, 1999.

BUDAG, F. E. Intertextualidade, dialogismo e cultura material: um estudo de narrativa ficcional audiovisual contemporânea. Tese (Doutorado em Ciências da Comunicação) - Universidade de São Paulo, São Paulo, 2017.

CAMPBELL, J. O herói de mil faces. São Paulo: Pensamento, 2007.

CUNHA, M. Z. C. Apresentação: Bem-vindas, vívidas forças da magia. In: VALENZUELA, Sandra T. Once Upon a Time: da literatura para a série de TV. Lisboa: Chiado, 2016, p. 11-16.

ECO, U. O nome da Rosa. 2. ed. Rio de Janeiro: Record, 2010.

GENETTE, G. Palimpsestos: a literatura de segunda mão. Belo Horizonte: Faculdade de Letras da UFMG, 2005.

MAFFESOLI, M. Sobre o nomadismo: vagabundagens pós-modernas. Rio de Janeiro: Record, 2001.

MITTELL, J. Complexidade narrativa na televisão americana contemporânea. Revista Matrizes, São Paulo, v. 5, n. 2, p. 29-52, jan./jun. 2012.

PILLAR, A. D. Inscrições do contemporâneo em narrativas audiovisuais: simultaneidade e ambivalência. Revista Educação, Porto Alegre, v. 36, n. 3, p. 306-313, set./dez. 2013.

PONTES, E. L.; SANTOS, C. M. O Comportamento dos Fandoms a partir do ato de Shippar: um estudo de caso em Once Upon a Time. In: CONGRESSO BRASILEIRO DE 
CIÊNCIAS DA COMUNICAÇÃO, 39., 2016, São Paulo. Anais... São Paulo: Intercom, 2016. Disponível em: <https://goo.gl/kmhqu2>. Acesso em: 13 out. 2017.

POMMER, M. E. As duplas vidas nas séries televisivas. In: BORGES, G.; PUCCI, R.; SELIGMAN, F. (Eds.). Televisão: Formas audiovisuais na ficção e no documentário. São Paulo: Socine, 2011. p. 129-140.

SILVA, M. V. B. Cultura das séries: forma, contexto e consumo de ficção seriada na contemporaneidade. Revista Galáxia, São Paulo, v.14, n. 27, p. 241-252, jun. 2014.

TODOROV, T. Introdução à Literatura Fantástica. 4. ed. São Paulo: Perspectiva, 2014.

VALENZUELA, S. T. Once Upon a Time: da literatura para a série de TV. Lisboa: Chiado, 2016.

Branca de Neve e o Príncipe Encantado: personagens de Once Upon a Time. Revista Literartes, São Paulo, n. 3, p. 155-169, 2014.

submetido em: 10 jul. 2017 | aprovado em: 28 jul. 2017 